\title{
Inventário de Questões Instigantes sobre Raça e Cor e a Atualidade de Guerreiro Ramos
}

\author{
Marcelo Henrique Romano Tragtenberg ${ }^{1}$ \\ Universidade Federal de Santa Catarina, Florianópolis, Brasil \\ E-mail: marcelotragtenberg@gmail.com
}




\section{Resumo}

Guerreiro Ramos abordou vários aspectos da condição do negro no Brasil. Seus estudos trouxeram um conjunto de questões teóricas ligadas à prática política e social, que poderiam, segundo seu ponto de vista, conduzir o Brasil para uma situação de maior igualdade racial e para a diminuição do racismo e da discriminação racial. Alguns deles serão analisados neste artigo.

Palavras-chave: Raça. Racismo. Desigualdades Raciais. Brancura. Ações Afirmativas.

\section{Abstract}

Guerreiro Ramos studied many aspects of the Black condition in Brazil. He raised a set of theoretical questions related to the social and political practices that might contribute to promote racial equality and reduce racism and racial discrimination in Brazil. Some of them will be analyzed in this article.

Keywords: Race. Racism. Racial Inequalities. Whiteness. Affirmative Action. 


\section{Introdução}

— sta breve reflexão tem origem devido ao convite da Professora Ilka Boaventura Leite e da coordenação do Seminário em homenagem aos 100 anos de nascimento de Alberto Guerreiro Ramos para que eu coordenasse a mesa Pensamento social sobre Raça e Cor, e sou muito grato por esse convite. Inicialmente, estava prevista a participação de dois palestrantes, os professores João Baptista Borges Pereira (Universidade de São Paulo) e Marcos Chor Maio (Fundação Oswaldo Cruz). Somente o segundo compareceu, pois o primeiro teve problemas de saúde. O fato de estar na coordenação da mesa me instigou a tomar contato com o artigo do professor Marcos sobre Guerreiro Ramos (Maio, 1997), base de sua contribuição, e contrastá-lo com parte da produção do ilustre sociólogo negro. Por que lembrar a raça desse pensador? Espero responder a essa questão ao longo deste artigo.

Busca-se aqui levantar um repertório original de temas polêmicos sobre a questão racial que ainda mantém grande atualidade, por vários motivos: (a) a situação de desigualdade racial entre negros e brancos não avançou significativamente desde 1950 até hoje; (b) esse tema atualmente ocupa um lugar de destaque na sociedade brasileira; e (c) estão começando a ser adotadas políticas de igualdade racial com algum impacto, há cerca de 15 anos. No entanto, este artigo está longe de esgotar o conjunto de questões teóricas e metodológicas e suas atualizações, que surgem a partir da obra de Guerreiro Ramos no tocante à questão racial no Brasil. A atualização desses temas também é uma reflexão concisa e inicial sobre como os temas guerreireanos podem contribuir para o entendimento e a superação das profundas desigualdades raciais brasileiras. 
A próxima seção deste artigo tratará desse inventário de uma série de temas abordados por Guerreiro Ramos em relação à raça e cor no Brasil. A segunda seção tratará da atualidade desses temas de relações raciais no Brasil.

\section{Inventário de Temas Relevantes sobre Relações Raciais na Obra de Guerreiro Ramos}

1) Em ciência, parte-se da colocação de um problema, geralmente sobre a forma de uma questão. A pesquisa busca então respostas a essa questão. Guerreiro Ramos (1995, p. 190) ressaltou que:

Em princípio, o negro, no domínio da sociologia brasileira, foi problema porque seria portador de traços culturais vinculados a culturas africanas [...] Hoje continua a ser assunto ou problema, porque tende a confundir-se pela cultura com as camadas mais claras da população brasileira [...] Que é que, no domínio de nossas ciências sociais, faz do negro um problema, ou um assunto? A partir de que norma, de que padrão, de que valor, se define como problemático ou se considera tema o negro no Brasil?

E vai além:

Determinada condição humana é erigida à categoria de problema quando, entre outras coisas, não se coaduna com uma ideia, um valor ou uma norma.

[...] Nessas condições, o que parece justificar a insistência com que se considera como problemática a situação do negro no Brasil é o fato de que ele é portador de pele escura. A cor da pele do negro parece constituir o obstáculo, a anormalidade a sanar. (Guerreiro Ramos, 1995, p. 190 e 192)

Em outras palavras, o problema do negro era um problema relevante da sociologia. O negro era visto como um problema a ser resolvido, algo que atrapalhava a normalidade das relações sociais. Guerreiro Ramos (GR) mostrou o lado discriminatório e racista desse tipo de colocação dentro do âmbito sociológico e social. Interessante que mesmo quando o negro adquiria a mesma cultura e nível socioeconômico 
dos grupos sociais de pele mais clara, ele continuava a ser problema. O marcador dessa "anormalidade" seria a cor da pele, segundo GR. Isso era totalmente coerente com a abordagem de Oracy Nogueira (2006), segundo a qual o preconceito que gera o problema do negro, no Brasil, é de marca e não de origem. Atualmente, como veremos mais à frente, o enfoque e a própria formulação do problema mudou totalmente e seria inconcebível colocá-lo dessa forma sem sofrer uma acusação (justificada) de racismo.

2) Outro aspecto bastante interessante e que vai se refletir em outros temas ligados a raça e cor em Guerreiro Ramos é a necessidade de analisar o comportamento dos brancos frente aos negros, ou como ele se refere à ideologia da brancura. Como a centralidade do branco seja no valor estético ou no econômico é vista a partir de uma construção ideológica e psicossocial? Veremos que isso é assunto bastante atual. Particularmente, o Teatro Experimental do Negro, movimento do qual Guerreiro Ramos participou, estimulava concursos de beleza, onde a beleza negra era valorizada, como "Rainha das Mulatas" e "Bonecas de Pixe". Ressalta-se que hoje essa terminologia talvez fosse considerada hoje inadequada, até ofensiva, por alguns. No entanto, vistos em perspectiva histórica, a partir da época em que ocorreram, esses concursos de beleza eram instrumentos de valorização da beleza das mulheres negras.

[...] Na verdade, utilizando observação de Sartre, podese dizer que, no Brasil, o branco tem desfrutado do privilégio de ver o negro, sem por este ser visto [...] O que nos interessa aqui é focalizar a questão do ângulo psicológico, enquanto socialmente condicionado, é atingir a sociologia funcional e científica do negro, inteiramente por fazer até agora, desde que os estudos da questão que se rotulam de sociológicos e antropológicos não são mais do que documentos ilustrativos da ideologia da brancura ou claridade. (Nogueira, 2006, p. 196-196-202)

Além do privilégio socioeconômico e estético da brancura, Guerreiro Ramos aponta a necessidade dos brancos serem analisados do ponto de vista dos negros. Sabemos que uma análise pode depender do ponto de vista do analista, levando em conta uma serie 
de características, histórias de vida, metodologia e até ideologia do autor. Um fator possível é a raça. Isso não significa que a raça, ou qualquer outro fator, determine a posição do autor, mas que pode influenciar nela.

3) Os desequilíbrios sociais entre negros e brancos apareceram em vários momentos da obra de GR. Particularmente, as suas noções de integração e ascensão social do negro na sociedade brasileira se opunham ao conceito de aculturação do negro. Por exemplo, as religiões de matriz africana não eram exclusividade da população negra, tornando anacrônico o conceito de aculturação. No entanto, o pensador via a necessidade de uma longa formação do homem de cor, pois ele “[...] não estaria habilitado às funções de mando, as quais, como é sabido, supõe uma longa aprendizagem [...]" (Guerreiro Ramos, 1950a).

Além disso, ele integra-se ao Teatro Experimental do Negro (TEN), fundado em 1944 por Abdias do Nascimento, que tinha, sob seu ponto de vista, “[...] três objetivos fundamentais: 1) formular categorias, métodos e processos científicos destinados ao tratamento do problema racial no Brasil; 2) reeducar os "brancos" brasileiros, libertando-os de critérios exógenos de comportamento; 3 ) “[...] descomplexificar os negros e mulatos, adestrando-os em estilos superiores de comportamento, de modo que possam tirar vantagem das franquias democráticas, em funcionamento no país." (Guerreiro Ramos, 1995, p. 206).

Abdias do Nascimento, na Conferência Nacional do Negro, patrocinada pelo TEN em 1949, teria dito: "A mentalidade de nossa população de cor é ainda pré-letrada e pré-lógica. As técnicas sociais letradas ou lógicas, os conceitos, as ideias, não a atingem" (Maio, 1997, p. 6)

A condição jurídica de cidadão livre dada ao negro (pela Abolição) foi um avanço sem dúvida. Mas um avanço puramente simbólico, abstrato. Socioculturalmente, aquela condição não se configurou; de um lado, porque a estrutura de dominação da sociedade brasileira não se alterou; de outro lado, porque a massa juridicamente libertada estava psicologicamente despreparada para assumir as funções de cidadania. Assim, para que o processo de libertação dessa massa se positive, é necessário reeducá-la e criar condições sociais para que esta reeducação se efetive. A simples reeducação desta 
massa desacompanhada de correlata transformação da realidade sociocultural representa a criação de situações marginais dentro da sociedade. É necessário instalaremse na sociedade brasileira mecanismos integrativos de capilaridade social capazes de dar função e posição aos elementos da massa de cor que se adestrarem nos estilos das classes dominantes. (Guerreiro Ramos, 1995, p. 207)

Muitas vezes, como no livro de Clóvis Moura (1983) ou em Maio (1997), essa visão da população negra poderia parecer elitista ou ambígua, respectivamente. Elitista por considerar pré-letrado, pré-lógico e "inatingidos" por ideias ou conceitos, na formulação de Abdias, do TEN, organização à qual Guerreiro Ramos pertenceu. Ambígua porque

[...] oscilou entre o reconhecimento dos legítimos direitos do povo negro à cidadania plena e o diagnóstico da incapacidade temporária dos negros de exercer a política por terem uma mentalidade pré-lógica, pré-letrada. (Maio, 1997, p. 6)

Inicialmente, não se vê qualquer ambiguidade entre visualizar direitos e simultaneamente encarar a realidade da falta de acesso de negros aos instrumentos necessários à política, como por exemplo, a educação formal. O percentual de analfabetos entre pretos e pardos era bem superior ao de brancos, ao redor de 1950. Segundo Rosemberg e Piza (1995/1996), o percentual de analfabetos pretos e pardos era de aproximadamente $75 \%$ e de brancos era de $47 \%$. Porém, José Luís Petruccelli (apud Senkevics, 2015) apresenta os percentuais de 40\% e $62 \%$, respectivamente. Essa brutal desigualdade de acesso às letras poderia justificar o qualificativo pré-letrado. Como não há estatísticas de analfabetismo funcional por cor/raça em 1950, não é possível ir além com relação ao argumento da grande distância entre as letras e os negros. Além disso, o acesso percentual ao ensino superior da população negra em 1960 era de 0,16\%, (Telles, 2003)! Dez anos depois havia pouquíssimos quadros negros com ensino superior no Brasil, contra 2,5\% da população branca (Telles, 2003), aproximadamente 16 vezes mais. Extrapolando para 1950, a situação devia ser muito pior.

Na crítica ao elitismo, creio ser possível outra interpretação, mais condescendente com as palavras de Guerreiro Ramos e Abdias. 
O elitismo, segundo Moura (1983) e Maio (1997), seria conceber que a população negra de baixa renda não teria condições de formular reivindicações e lutar por elas. A incipiência do Movimento Negro enquanto movimento por igualdade racial na época aponta exatamente nesse sentido. Por outro lado, a dificuldade da formulação de uma teoria antirracista que elaborasse uma pauta de reivindicações de igualdade racial (com poucos intelectuais e militantes diretamente envolvidos) e a prevalência da ideologia da democracia racial eram grandes aliados da permanência das desigualdades raciais.

É preciso ressaltar que Guerreiro Ramos chama a atenção em três campos de combate pela igualdade racial: a internalização da situação inferior como complexo - presente também em Fanon (2008) - a reeducação (formal e cultural) e a criação de mecanismos sociais de integração de elementos da massa de cor em posições de prestígio (criação de modelos sociais).

Ele não crê num movimento social organizado e de massas destinado a mudar estruturas sociais e políticas públicas e privadas.

4) Talvez uma das questões mais atuais, colocada por Guerreiro Ramos a partir da década de 1950, foi sobre os estudos sobre o negro no Brasil. Ele opunha duas posições: uma "Caracterizava-se pelo propósito antes de transformar a condição humana do negro na sociedade brasileira do que de descrever ou interpretar os aspectos pitorescos e particularíssimos da situação da gente de cor." (Guerreiro Ramos, 1995, p. 169).

Nessa polêmica apareceram duas dimensões de contradição: descrição dinâmica x estática da condição do negro no Brasil e o propósito transformador da condição humana do negro $\mathrm{x}$ a descrição academicista sem compromisso com a transformação. A visão dinâmica e comprometida objetiva a superação de uma situação herdada da escravidão e reatualizada pelo racismo e a discriminação racial. A outra, ao contentar-se com a descrição e a espetacularização da posição social do negro concorre para a reprodução da posição subalterna desse grupo social.

Talvez seja essa a questão que mais coloque o compromisso social de quem estuda a condição do negro no Brasil. Quanto o estudo da situação está voltado para superação dessa condição subalterna? 
Esse tema é atualíssimo, particularmente na questão das cotas para negros, cotas raciais ou cotas para pretos e pardos. Mas isso é assunto para a atualização.

5) Talvez uma das questões que têm dado origem a opiniões apaixonadas, tanto na sociedade quanto no ambiente acadêmico, seja o conceito de negro. Como o conceito de negro implica na necessidade de conceituar o branco, Guerreiro Ramos construiu o conceito de patologia social do "branco" brasileiro. Ele parte do fato de que em nossa sociedade é considerado normal associar a cor negra ao feio e degradante este conceito, por meio de um processo complexo comandado pela minoria socialmente dominante de origem europeia. No entanto, pessoas de pigmentação mais clara que tiveram ancestrais negros ao mesmo tempo podem ter um sentimento negativo em relação a si, pois negam suas origens, particularmente no Norte e Nordeste. Essa seria a patologia social do "branco" brasileiro. Várias pessoas negras também manifestam esse sentimento, ligado à introjeção da desvalorização social do negro. “[...] o nosso branco é, do ponto de vista antropológico, um mestiço, sendo, entre nós, pequena minoria o branco não portador de sangue negro" (Guerreiro Ramos, 1995, p. 225). Essa patologia psicossocial se superporia ao passado colonial, seja como colônia explícita de Portugal, seja como neocolônia da Inglaterra e Estados Unidos. A superposição dessas situações inferiorizadoras pode ser uma das origens ao chamado complexo de vira-lata (Rodrigues, 1993), um sentimento disseminado nacionalmente, que nos coloca como inferiores aos chamados países desenvolvidos. A afirmação guerreireana parece ter uma contradição entre o ponto de vista antropológico e o ponto de vista da ascendência. Oracy Nogueira detectou dois tipos básicos de preconceito racial: o preconceito de marca e o de origem (Nogueira, 2006). A definição de negro no Brasil estaria ligada à forma com que se dá a discriminação racial, ou seja, pela marca, e não pela origem. Mas Guerreiro Ramos mostra outro aspecto: apesar do negro e do branco ser definido pelas marcas raciais, ou seu fenótipo, há um aspecto que mereceu sua atenção, que é como um grupo social repudia a sua ancestralidade biológica e como esse estado patológico de autonegação pode gerar consequências em nível social nacional e 
de relação internacional. Uma dessas consequências já foi enunciada na ideologia da brancura, a outra é o complexo de vira-latas e uma terceira é a discriminação racial contra negros, como negação do outro que está dentro de si. Nesse ponto, Guerreiro Ramos menciona a "reeducação de brancos e brancóides" (Guerreiro Ramos, 1950b) para minimizar o racismo, particularmente entre as camadas mais altas.

6) Uma questão teórica fundamental para explicar os mecanismos de geração de desigualdade na sociedade brasileira, e as formas de superá-los é se o conceito de raça tem determinação independente de desigualdade, ou se ele é redutível ao conceito de classe. Essa é uma questão extremamente relevante tanto na sociologia quanto nas políticas públicas para a igualdade racial. Luiz Costa Pinto, polemista com Guerreiro Ramos (Maio, 1997) projeta a superação do racismo condicionada à transformação da raça em classe, sendo o motor da transformação redentora o proletariado (Costa Pinto, 1953, p. 338). Na mesma linha, Florestan Fernandes (1965) e Octavio Ianni (1988; 2004), mesmo entendendo que o preconceito racial não se reduz ao preconceito de classe, alegam que a superação da estrutura de classes sociais que deve trazer o fim do racismo.

Guerreiro Ramos aponta uma dimensão interessante da integração do negro em Maio (1997), sua trajetória pessoal como negro melhorando de vida continua sem ser aceito socialmente. Não basta ter a cultura, ensino superior e o traquejo das regras sociais dos brancos, que sempre será negro. Isso já é indicação de que mesmo uma revolução social não traria o fim do racismo e das desigualdades raciais

7) Guerreiro Ramos buscava originalidade na formulação sociológica (sociologia enlatada 78, primeira edição de Introdução à Sociologia Brasileira) contra comportamento enlatado, importado de outros países. Isso se aplicava particularmente às relações raciais.

8) Uma perspectiva auxiliar na libertação dos negros, segundo GR, era a superação psicológica dos ressentimentos e das ansiedades, criados pelo racismo e pela discriminação racial. A grande política das relações raciais se materializava num ataque psíquico ao negro. A libertação passava por trabalhar esses sentimentos e buscar resolvê-los. Propostas para isso foram levadas a cabo no TEN, por Guerreiro Ramos. 
9) Valorizar a herança africana como forma de valorizar o negro brasileiro não era uma estratégia valorizada por GR, mas vista como apartamento da sociedade nacional brasileira, com características mais urbanas e industriais. A postura do Movimento Negro hoje é muito diferente.

10) Guerreiro Ramos não teve acesso a um cargo efetivo numa universidade brasileira, sua posição mais longeva foi numa estadunidense. Não foi aprovado em duas tentativas de concursos na Universidade Federal do Rio de Janeiro e foi professor visitante da Universidade Federal de Santa Catarina, na Pós-Graduação em Administração. Maio (1997) comenta que o sociólogo atribuiu a seu pertencimento integralista a dificuldade de ingresso na UFRJ. No entanto, esse aspecto de sua vida coloca questões sobre igualdade racial na academia e problematiza essa questão como a possibilidade de racismo institucional (Figueiredo; Grosfoguel, 2007).

\section{Atualidade de Temas sobre Relações Raciais na Obra de Guerreiro Ramos}

Neste artigo foram listados dez temas não necessariamente excludentes colocados a partir da obra e atuação de Guerreiro Ramos. Esta seção objetiva mostrar a atualidade desses temas e como algumas proposições guerreireanas podem contribuir para uma reflexão e uma ação transformadora da realidade.

1) No Brasil atual, continuam as desigualdades raciais, entre brancos e negros (Henriques, 2001). No entanto, nenhum estudioso do assunto se referiria a isso como o "problema do negro". Essa expressão denota que o problema é o negro e não a discriminação racial e o racismo, que em conjunto com a herança escravocrata, constroem as desigualdades raciais. Os conceitos atualmente utilizados são desigualdades raciais e relações raciais, a ênfase é no conceito social de raça e na injustiça construída a partir de relações entre raças. Assim, na sequência, surge naturalmente a questão que o problema do negro na sociedade brasileira é a existência de um padrão: vamos para o item 2, a brancura hoje é a branquitude e o a estética valorizada ainda é a branca. 
2) Recentemente, o estudo de relações raciais tem ido além do foco na discriminação racial no Brasil. Um aspecto evocado por Guerreiro Ramos é o estudo da identificação racial branca e de seus privilégios associados. A elaboração do conceito de branquitude (whiteness em inglês), no Brasil, aparece no artigo de Carone e Bento (2002). O estudo do branco é recente. Manifestações públicas de discriminação estética mostram os bolsões de brancos que cultivam a estética da brancura ou da branquitude. O caso das agressões em redes virtuais à moça do tempo do Jornal Nacional da TV Globo, Maria Júlia Coutinho; à atriz Tais Araújo e à atriz e modelo Cris Vianna, todas elas muito bonitas mostram o repúdio de setores sociais para a valorização da estética negra. O caso recente da chamada Mulata Globeleza preta, Nayara Justino, que foi demitida durante um processo de divulgação do carnaval, por ser muito escura, mostra o longo caminho de desconstrução da branquitude e seus privilégios, que prejudicam a negros e brancos.

3) Os desequilíbrios entre brancos e negros persistem na década de 2010, mas as estratégias para superá-los conjugam políticas universalistas e de ação afirmativa, ambas dentro da ordem e buscando aperfeiçoamento e minimização das desigualdades raciais. Quanto mais se estuda o tema, mas parece que a igualdade racial está muito distante, talvez em escala de séculos.

4) Talvez uma das posturas de Guerreiro Ramos que tenha mais relevância atualmente seja a conexão do estudo da situação dos negros e brancos no Brasil com a elaboração de políticas. A sociologia militante de Guerreiro Ramos buscava levantar propostas que efetivamente pudessem melhorar a vida da população negra, em direção à igualdade racial. A política de cotas com recorte racial, no acesso às universidades públicas (Lei n. 12.711/2012), privadas (PROUNI), ao serviço Público Federal (Lei n. 12.990/2013) e aos serviços públicos estaduais e municipais, são exemplos disso. Alguns exemplos de áreas em que os estudos poderiam contribuir enormemente para a igualdade racial é no acesso de negros às ciências exatas e engenharia, ao ensino de matemática, à tecnologia digital e à língua inglesa, que serão gargalos de igualdade racial num futuro próximo. A reação de uma intelectualidade e uma mídia contra as políticas de ação afirmativa com recorte racial sem 
propor alternativa de políticas para igualdade racial demonstra como parcelas da sociologia e a antropologia brasileira se afastam do ideal militante de Guerreiro Ramos.

5) O conceito de negro atualmente tem definição jurídica pelo fenótipo (Nogueira, 2006), dada pelo parecer do Ministro Ricardo Lewandowski, do Supremo Tribunal Federal, aprovado por unanimidade, e admite verificação de pertencimento a raça, para evitar fraudes em políticas de ação afirmativa (Lewandowski, 2012). No entanto, a abordagem guerreireana da patologia social do "branco" brasileiro introduz uma riqueza de elaboração do preconceito do branco com sua própria ascendência negra, que o inferioriza e merece atenção na luta contra o racismo. Pena e Bortolini (2004) mostrou que cerca de $80 \%$ dos brasileiros têm ascendência africana, por meio de estudos de marcadores genéticos. Talvez esse argumento objetivo ajude a desmontar subjetividades preconceituosas com suas ascendências.

6) O tema da independência ou não do racismo como gerador de desigualdades em relação à diferença de classe ou renda continua atual. Essa matéria não pode ser avaliada de forma genérica, independente da área da sociedade. O aumento do salário mínimo e o programa Bolsa Família tiveram grande impacto na população negra, mesmo sendo políticas universalistas. Por outro lado, simulações sobre a adoção de cotas para egressos de escolas públicas na UFSC, mostraram que cotas para escola pública não inclui negros (Tragtenberg et al., 2006). Há várias indicações que em muitos campos da sociedade brasileira políticas universalistas são insuficientes para superar desigualdades raciais. (Telles, 2003). No plano internacional, a revolução cubana foi também insuficiente para superar as diferenças entre brancos e negros (Castro, 2000).

7) O pensamento original calcado na realidade e na tradição histórica brasileira, como indica metodologicamente GR, inspirou, por exemplo, uma das mais importantes ferramentas jurídicas para ação afirmativa para negros no Brasil. O parecer do ministro Lewandowski (2012) valida a política de reserva percentual de vagas (cotas) ou bônus para negros, ao contrário da Suprema Corte dos EUA. Tanto cotas como bônus são inconstitucionais nos EUA desde 1974 e 2001, respectiva- 
mente. Além disso, como a forma de discriminação no Brasil é pela aparência, isso ficou consignado no parecer, bem como a possibilidade de proceder à fiscalização do beneficiário das cotas para negros.

8) Atualmente, e vou me deter somente a um tópico de pressão psíquica, negros e membros de minoria sentem a ameaça pelo estereótipo (Steele, 1995). Além de outras disfunções por discriminação, o sentimento que vai falhar porque seu grupo social falha em determinados desafios leva efetivamente a uma falha. A pesquisa sobre como o racismo pode influenciar na performance de negros em testes é muito importante para minimizar a desigualdade racial.

9) No Brasil atual, o Movimento Negro vem construindo a valorização da herança africana, em oposição a posições guerreireanas. A Lei n. 10.639/2003 e a Lei n. 11.645/2008 seguem o sentido da valorização da história africana, afro-brasileira e dos negros no Brasil.

10) Recentemente, a ação afirmativa para o ingresso de negros na academia foi regulamentada através da Lei n. 12.990/2014, que reserva $20 \%$ para negros em concursos públicos federais. No entanto, há gargalos a serem vencidos: há poucos doutores negros; o percentual de $20 \%$ é preenchido em muitas áreas, mas será eficaz em áreas muito seletivas, embora se encontre ainda longe do quantitativo para igualdade racial e, por fim, universidades tentam burlar a cota confundindo a reserva percentual no conjunto das vagas com a reserva percentual por área de conhecimento de concurso. Como em geral se abrem poucas vagas por área, em muitos editais as cotas para negros são inócuas, poucas vagas são reservadas.

\section{Conclusões e Perspectivas}

Guerreiro Ramos foi um sociólogo com várias elaborações originais sobre as relações raciais no Brasil. Vários temas por ele abordados continuam atuais e outros originaram novas políticas de igualdade racial. Reler Guerreiro Ramos é repensar sempre de um ponto de vista criativo as várias facetas dos efeitos da discriminação racial no Brasil. Sua trajetória se encaixa nisso. Ele é uma inspiração para pensar de forma própria as soluções para as desigualdades raciais brasileiras, que abrangem tantos domínios como as ciências exatas, a engenharia, 
a tecnologia e o acesso a tudo isso, a educação básica, o mundo do trabalho, a estética valorizada socialmente e o impacto psíquico do preconceito racial, entre outros.

\section{Notas}

1 Departamento de Física da Universidade Federal de Santa Catarina (UFSC). Presidente da Comissão Institucional de Acompanhamento e Avaliação da Política de Ações Afirmativas da UFSC. Diretor Administrativo da Secretaria de Ações Afirmativas e Diversidades da UFSC. Pesquisador do Instituto Nacional de Ciência e Tecnologia de Inclusão no Ensino Superior e na Pesquisa do Conselho Nacional de Desenvolvimento Científico e Tecnológico (INCTI/CNPq).

\section{Referências}

CARONE, Iray; BENTO, Maria Aparecida Silva. Branqueamento e Branquitude no Brasil. In: CARONE, Iray; BENTO, Maria Aparecida Silva. (Org.). Psicologia social do racismo: estudos sobre branquitude e branqueamento no Brasil. Petrópolis, RJ: Vozes, 2002. p. 25-58.

CASTRO, F. Discurso na Igreja da Marginal do Rio do Harlem. 2000. Disponível em: <http://www.afrocubaweb.com/fidelcastroriversidespeech. htm >. Acesso em: 22 jun. 2016.

COSTA PINTO, L. O Negro no Rio de Janeiro: relações de raças numa sociedade em mudança. São Paulo, Companhia Editora Nacional, 1953.

FANON, F. Pele negra, máscaras brancas. Tradução de Renato da Silveira. Salvador: EDUFBA, 2008.

FERNANDES, F. A integração do negro na sociedade de classes: o legado da "raça branca. São Paulo: Globo, 2008. v. 1.

FIGUEIREDO, A.; GROSFOGUEL, R. Por que não Guerreiro Ramos? Novos desafios a serem enfrentados pelas universidades públicas brasileiras.

Ciência e Cultura, São Paulo, v. 59, n. 2, Apr.-June, 2007.

GUERREIRO RAMOS, A. (Org.). O Negro no Brasil e um Exame de Consciência. Relações de Raça no Brasil. Rio de Janeiro, Edições Quilombo, 1950a.

1950b. Sobre as relações de raças. Sociologia, [S.l.], v. 12, n. 1, p. 3-21,

Introdução crítica à sociologia brasileira. Rio de Janeiro: UFRJ, 1995. 
HENRIQUES, R. Desigualdade racial no Brasil: evolução das condições de vida na década de 90. Texto para discussão n. 807. IPEA. Rio de Janeiro, 2001. Disponível em <http://repositorio.ipea.gov.br/handle/11058/1968>. Acesso em: 22 jun. 2016.

IANNI, Octavio. Escravidão e racismo. 2. ed. São Paulo, Hucitec, 1988.

IANNI, Octavio. O preconceito racial no Brasil. Revista Estudos

Avançados, São Paulo, v. 18, n. 50, jan.-apr. 2004. Disponível em: <http:// dx.doi.org/10.1590/S0103-40142004000100002 >. Acesso em: 13 jun. 2016.

\section{LEWANDOWSKI, R. Parecer sobre ação de descumprimento}

de Preceito Fundamental 186 (DEM contra Cotas da UnB), 2012. Disponível em: <http://www.stf.jus.br/portal/cms/verNoticiaDetalhe. asp?idConteudo $=205890>$. Acesso em: 22 jun. 2016.

MAIO, M. C. Uma polêmica esquecida: Costa Pinto, Guerreiro Ramos e o tema das relações raciais. Dados, Rio de Janeiro, v. 40, n. 1, 1997. Disponível em: <http://www.scielo.br/scielo.php?script=sci arttext\&pid $=$ S001 $1-525819970001000068 \operatorname{lng}=$ en\&nrm $=$ iso\&tlng $=\mathrm{pt}>$. Acesso em: 15 fev. 2016.

MOURA, C. Ideologia do branqueamento das elites brasileiras e dilemas da negritude. In: BRASIL. Raízes do protesto negro. São Paulo: Global, 1983, p. 40-46 e 100-105.

NOGUEIRA, O. Preconceito racial de marca e preconceito racial de origem: Sugestão de um quadro de referência para a interpretação do material sobre relações raciais no Brasil. Tempo Social, Revista de Sociologia da USP, São Paulo, v. 19, n. 1, p. 287-308, 2006. Disponível em: < http://www. scielo.br/pdf/ts/v19nl/al5v19nl.pdf>. Acesso em: 16 jun. 2016.

PENA, S. D. J.; Bortolini, M. C. Pode a genética definir quem deve se beneficiar das cotas universitárias e demais ações afirmativas? Estudos Avançados, [S.l.], v. 18, n. 50, p. 31, 2004.

RODRIGUES, N. Complexo de vira-latas. In: Castro, R. À sombra das chuteiras imortais: crônicas de chutava. São Paulo, Companhia das Letras, 1993.

ROSEMBERG, F.; PIZA, E. Analfabetismo, gênero e raça no Brasil. Revista USP, São Paulo, v. 28, n. 110-121, dez.-fev. 1995/1996.

SENKEVICS, A. A cor e a raça nos censos demográficos nacionais. [2015]. Disponível em: < https://ensaiosdegenero.wordpress. com/2015/02/13/a-cor-e-a-raca-nos-censos-demograficos-nacionais/>. Acesso em: 13 fev. 2015. 
STEELE, Claude M.; ARONSON, Joshua. Journal of Personality and Social Psychology, [S.l.], v. 69, n. 5, p. 797-811, nov. 1995. Disponível em: <http://dx.doi.org/10.1037/0022-3514.69.5.797>. Acesso em: 13 jun. 2016. TELLES, Edward. Racismo à brasileira: uma nova perspectiva sociológica. Rio de Janeiro: Relume-Dumará: Fundação Ford, 2003.

TRAGTENBERG, M. H. R. et al. Como aumentar a proporção de estudantes negros na universidade? Cadernos de Pesquisa, [S.l.], v. 36, n. 128, p. 473-495, maio-ago. 2006.

Recebido em 24/01/2016

Aceito em $1 \% 03 / 2016$ 